\title{
Manajemen Kecemasan pada Pasien yang Menjalani Pembedahan Jantung
}

\author{
Bambang Aditya Nugraha ${ }^{1}$, Sandra Pebrianti ${ }^{2}$, Hesti Platini $^{3}$, Gusgus Ghraha Ramdhanie ${ }^{4}$
}

\begin{abstract}
Abstrak
Kecemasan merupakan permasalahan yang ditemukan pada pasien dengan penyakit jantung dan bertambah saat pasien harus menjalani prosedur pembedahan jantung. Pengelolaan kecemasan harus dilakukan untuk mencegah perburukan hemodinamik dan neurohormonal pasca pembedahan. Dengan demikian menjadi penting untuk mengidentifikasi intervensi manajemen kecemasan dalam rangka meningkatkan proses pemulihan pasca pembedahan dan meningkatkan kualitas hidup pasien. Tujuan dari penyusunan tinjauan literatur ini adalah untuk mengidentifikasi intervensi keperawatan terkait manajemen kecemasan. Metode penelusuran menggunakan beberapa database google scholar dengan menggunakan kriteria inklusi yang berfokus pada manajemen kecemasan pasien yang menjalani prosedur pembedahan jantung, tahun publikasi antara 2010-2020, berupa artikel lengkap, berbahasa Indonesia dan Inggris. Hasil penelusuran menemukan sebanyak 62 artikel, 27 memenuhi kriteria tahun dan sebanyak 13 merupakan artikel lengkap. Dan terakhir ditemukan sebanyak 6 artikel yang sesuai dengan fokus pencarian. Intervensi manajemen kecemasan secara umum dikelompokan menjadi teknik relaksasi dan suportif edukatif. Teknik relaksasi dan intervensi suportif edukatif menjadi intervensi yang dapat dipertimbangkan untuk digunakan pada manajemen kecemasan demi meningkatkan proses pemulihan pasca bedah dan kualitas hidup.
\end{abstract}

Kata kunci: kecemasan, manajemen kecemasan, pembedahan jantung.

\begin{abstract}
Anxiety is a problem that found in patients with heart disease. Anxiety will increase when the patient has to undergo the cardiac surgery procedure. Anxiety management must be conducted to prevent postoperative hemodynamic instability and neurohormonal deterioration. Thus it becomes important to formulate the anxiety management to improving the recovery process after surgery and patients quality of life of. The purpose of this literature review is to identify anxiety management on cardiac surgery patient. The search method uses Google Scholar databases using inclusion criteria proposed in consideration management that support heart surgery procedures, the year of publication between 2010-2020, containing the full article, in bahasa and english. Search results found 62 articles, 27 met the criteria of the year and 13 represented the complete article. And finally found as many as 6 articles that match the focus of the search. There are to type anxiety management e.g educational supportive and relaxation technique. Relaxation and supportive educative technique interventions can be used to manage anxiety to improve the postsurgical recovery process and quality of life.
\end{abstract}

Keywords: Anxiety, anxiety management, cardiac surgery

\section{PENDAHULUAN}

Gangguan kardiovaskular pada tahun

2008 dan lebih dari 23 juta orang akan meninggal setiap tahun dengan gangguan kardiovaskular. Lebih dari $80 \%$ kematian akibat gangguan kardiovaskular terjadi di negara-negara berpenghasilan rendah dan 
menengah (WHO, 2008). Prosedur pembedahan dilakukan sebagai upaya medikamentosa dalam rangka mengembalikan fungsi jantung.

Jenis pembedahan yang dilakukan diantaranya bypass arteri koroner, penggantian katup, koreksi aorta, transplantasi jantung dan sebagainya. Pembedahan merupakan prosedur yang menyebabkan stres karena berkaitan dengan ketidakpastian saat anestesi, rasa takut dan kecemasan (Ko, Y. L., \& Lin, P. C., 2012). Beberapa masalah dapat ditemukan pada pasien yang menjalani prosedur pembedahan jantung diantaranya syok kardiogenik, perdarahan, nyeri dan kecemasan. Permasalahan tersebut dapat mempengaruhi kondisi hemodinamik dan proses pemulihan pasca bedah. Kecemasan merupakan salah satu masalah psikologis pada pasien dengan penyakit jantung (Sulastini, S., Mediani, H. S., Fitria, N., \& Nugraha, B. A., 2019) dengan atau tanpa harus menjalani prosedur pembedahan. Pada pasien gagal jantung, kecemasan dan keletihan merupakan masalah yang dapat menurunkan produktivitas dan kualitas hidup .

Kecemasan pada pasien yang akan menjalanai prosedur pembedahan berkaitan dengan ketidaktahuan terkait prosedur dan masalah yang mungkin muncul akibat pembedahan (Nigussie, S., Belachew, T., \& Wolancho, W., 2014). Kecemasan pada pasien yang akan menjalani pembedahan jantung dapat menyebabkan perubahan hemodinamik yang dapat menghambat proses pembedahan. Dengan demikian menjadi penting untuk mengidentifikasi intervensi manajemen kelelahan pada pasien penyakit jantung yang akan menjalani prosedur pembedahan.

Tujuan dari tinjauan literatur ini adalah untuk mengidentifikasi intervensi keperawatan mandiri maupun komplementer dalam rangka pengelolaan kecemasan pada pasien yang akan menjalani prosedur pembedahan jantung.

\section{METODE PENELITIAN}

Metode penelusuran yang digunakan dengan pencarian artikel dar beberapa database, yaitu google scholar, ebsco dan proquest dengan menggunakan kriteria tertentu. Adapun kriteria yang digunakan adalah, artikel memiliki naskah lengkap, publikasi antara tahun 2010 sampai dengan tahun 2019, berbahasa Indonesia dan Inggris dan berfokus pada pengelolaan kecemasan pada pasien yang akan menjalani pembedahan jantung.

\section{HASIL DAN PEMBAHASAN}

\section{Hasil Penelitian}

Hasil penelusuran menemukan sebanyak 62 artikel, 27 memenuhi kriteria tahun dan sebanyak 13 merupakan artikel 
lengkap. Dan terakhir ditemukan sebanyak 6 artikel yang sesuai dengan fokus pencarian.

\begin{tabular}{|c|c|c|c|c|c|}
\hline No & Peneliti & Tahun & $\begin{array}{c}\text { Desai } \\
\mathbf{n}\end{array}$ & $\begin{array}{c}\text { Interve } \\
\text { nsi }\end{array}$ & $\mathbf{p}$ \\
\hline 1 & $\begin{array}{l}\text { Bagheri } \\
- \\
\text { Nesami, } \\
\text { M., } \\
\text { Shorofi, } \\
\text { S. A., } \\
\text { Zargar, } \\
\text { N., } \\
\text { Sohrabi, } \\
\text { M., } \\
\text { Gholipo } \\
\text { ur- } \\
\text { Baradari } \\
\text { A., \& } \\
\text { Khalilia } \\
\text { n, A. }\end{array}$ & 2014 & $\begin{array}{l}\text { Rando } \\
\text { mized } \\
\text { Contr } \\
\text { olled } \\
\text { Trial }\end{array}$ & $\begin{array}{l}\text { The } \\
\text { effects } \\
\text { of foot } \\
\text { reflexol } \\
\text { ogy } \\
\text { massage } \\
\text { on } \\
\text { anxiety } \\
\text { in } \\
\text { patients } \\
\text { followin } \\
\text { g } \\
\text { coronar } \\
\text { y artery } \\
\text { bypass } \\
\text { graft } \\
\text { surgery }\end{array}$ & $<0,001$ \\
\hline 2 & $\begin{array}{l}\text { Cutshall } \\
\text {, S. M., } \\
\text { Anderso } \\
\text { n, P. G., } \\
\text { Prinsen, } \\
\text { S. K., } \\
\text { Wentwo } \\
\text { rth, L. } \\
\text { J., } \\
\text { Olney, } \\
\text { T. L., } \\
\text { Messner } \\
\text {, P. K., } \\
\text {.. \& } \\
\text { Bauer, } \\
\text { B. A. }\end{array}$ & 2011 & $\begin{array}{l}\text { Rando } \\
\text { mized } \\
\text { Study }\end{array}$ & $\begin{array}{l}\text { Effect } \\
\text { of the } \\
\text { combina } \\
\text { tion of } \\
\text { music } \\
\text { and } \\
\text { nature } \\
\text { sounds } \\
\text { on pain } \\
\text { and } \\
\text { anxiety } \\
\text { in } \\
\text { cardiac } \\
\text { surgical } \\
\text { patients }\end{array}$ & $<0,001$ \\
\hline 4 & $\begin{array}{l}\text { Guo, P., } \\
\text { East, L., } \\
\& \\
\text { Arthur, } \\
\text { A. }\end{array}$ & 2012 & $\begin{array}{l}\text { Rando } \\
\text { mized } \\
\text { Contr } \\
\text { olled } \\
\text { Trial }\end{array}$ & $\begin{array}{l}\text { A } \\
\text { preopera } \\
\text { tive } \\
\text { educatio } \\
\mathrm{n} \\
\text { interven } \\
\text { tion to } \\
\text { reduce } \\
\text { anxiety } \\
\text { and } \\
\text { improve } \\
\text { recovery } \\
\text { among } \\
\text { Chinese } \\
\text { cardiac } \\
\text { patients }\end{array}$ & $<0,001$ \\
\hline 5 & $\begin{array}{l}\text { Heidari, } \\
\text { S., } \\
\text { Babaii, } \\
\text { A., } \\
\text { Abbasin } \\
\text { ia, M., } \\
\text { Shamali } \\
\text {, M., } \\
\text { Abbasi, } \\
\text { M., \& } \\
\text { Rezaei, }\end{array}$ & 2015 & $\begin{array}{l}\text { Rando } \\
\text { mized } \\
\text { Contr } \\
\text { olled } \\
\text { Trial }\end{array}$ & $\begin{array}{l}\text { The } \\
\text { effect of } \\
\text { music } \\
\text { on } \\
\text { anxiety } \\
\text { and } \\
\text { cardiova } \\
\text { scular } \\
\text { indices } \\
\text { in } \\
\text { patients }\end{array}$ & $<0,001$ \\
\hline
\end{tabular}

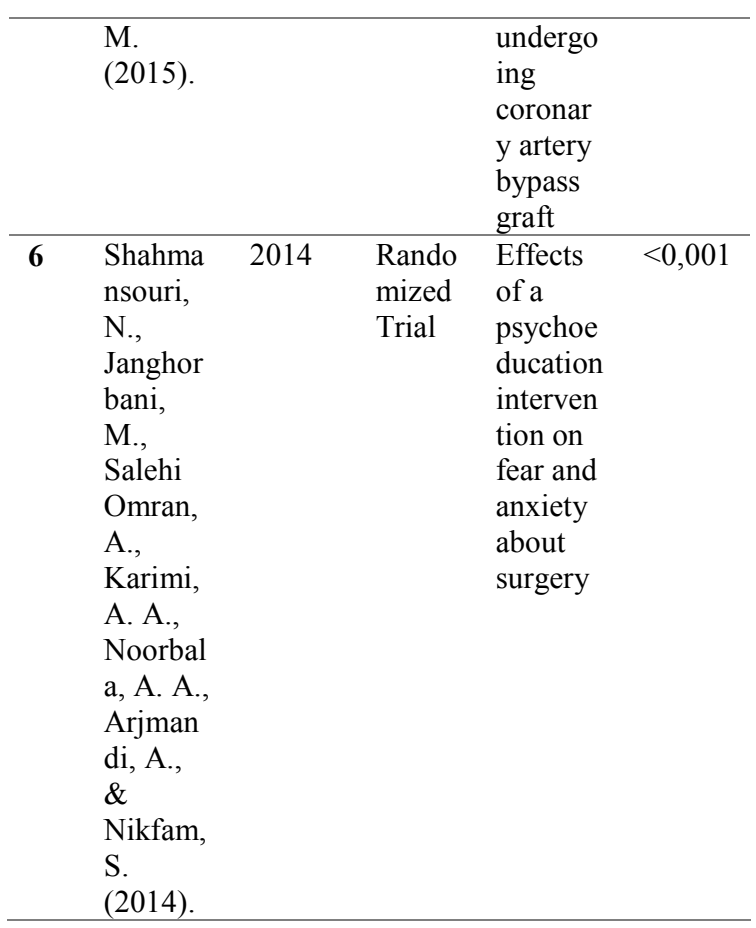

\section{Pembahasan}

Kecemasan pada pasien penyakit jantung berkaitan dengan banyak faktor. Faktor predisposisi seperti pasien khawatir dengan kondisi fisiknya yang lemah, takut bila penyakitnya tidak bisa sembuh karena jantung adalah organ vital dan ketika jantung mulai rusak maka hidup pasien juga terancam, menjalani terapi pengobatan yang lama dan panjang, prognosis penyakit yang memburuk, kepastian pengobatan yang akan ditempuh selanjutnya, jumlah biaya yang akan dihabiskan, lama waktu penyembuhan penyakitnya, sampai memikirkan tentang kematiannya (Fitriyani, 2015). Faktor predisposisi tersebut dapat menyebabkan masalah psikologis diantaranya gangguan psikososial seperti stress, kecemasan, dan ketidakberdayaan (powerlessness), selain itu ketakutan dan depresi juga bisa dialami 
pasien penyakit jantung (Polikandrioti et al, 2015). Dengan demikian, kecemasan sangat mungkin muncul pada pasien penyakit jantung meskipun tidak menjalani prosedur pebedahan

Manajemen kecemasan pada pasien penyakit jantung yang menjalani prosedur pembedahan bertujuan untuk mencegah efek kecemasan pada aspek fisik, diantaranya adalah perubahan nadi, abnormalitas tekanan darah, perubahan pada pernafasan yang akhirnya akan memperburuk perfusi dan sirkulasi. Teknik relaksasi terbukti dapat memperbaiki sirkulasi dengan menstimulasi limbik sistem di hipotalamus untuk mengeluarkan Corticotropin Releasing Factor (CRF) yang akan menstimulasi hipofise untuk meningkatkan produksi endorfine dan Pro Opioid Melano Cortin (POMC) yang akan meningkatkan produksi ensefalin oleh medula adrenal sehingga akan mempengaruhi suasana hati dan memberikan perasaan rileks (Black \& Hawks, 2010). Endorfine adalah hormon polipeptida yang mengandung 30 unit asam amino yang berikatan dengan reseptor opiat di otak, Hormon ini bertindak seperti morphine. Endorfine mampu menimbulkan perasaan euforia, bahagia, nyaman, menciptakan ketenangan dan memperbaiki suasana hati (mood) seseorang hingga membuat seseorang relaks (Black and Hawks, 2009).

Menurut Perry \& Potter (2005) dalam melaksanakan peranya, perawat seharusnya memberikan asuhan keperawatan secara holistik, meliputi biologi, psikologi, sosial, dan spiritual. Teknik relaksasi ini bermanfaat untuk mengatasi permasalahan psikologis responden yaitu cemas dengan teknik relaksasi seseorang akan merasakan perasaan nyaman secara fisik, perasaan nyaman secara fisik akan mempengaruhi kenyamanan psikologis. Perasaan nyaman baik secara fisik maupun psikologis salah satunya merupakan respon dari pengeluaran hormon endorfine (Newberg \& Waldman, 2013).

Upaya edukasi efektif mengatasi kecemasan. Beberapa penelitian menjelaskan bahwa ketidaktahuan adalah sumber kecemasan. Jika pengetahuan pasien dapat meningkat maka kecemaan dapat diatasi. Penelitian Guo, P., East, L., \& Arthur, A. (2012) telah menemukan bahwa upaya edukasi dapat menurunkan skor depresi dan kecemasan pada pasien yang akan menjalani pembedahan jantung.

\section{KESIMPULAN DAN SARAN}

\section{Kesimpulam}

Berdasarkan hasil penelusuran maka dapat disimpulkan bahwa teknik relaksasi tertentu dan upaya suportif edukatif efektif mengatasi kecemasan pada pasien yang akan menjalani prosedur pembedahan jantung.

\section{Saran}

Teknik relaksasi dan upaya suportif edukatif disarankan untuk dipertimbangkan 
sebagai intervensi keperawatan mandiri maupun komplementer dalam rangka pengelolaan kecemasan pada pasien yang akan menjalani pembedahan jantung

1, 2, 3, 4 Universitas Padjadjaran

Email: bambang14005@unpad.ac.id

\section{DAFTAR PUSTAKA}

Bagheri-Nesami, M., Shorofi, S. A., Zargar, N., Sohrabi, M., Gholipour-Baradari, A., \& Khalilian, A. (2014). The effects of foot reflexology massage on anxiety in patients following coronary artery bypass graft surgery: a randomized controlled trial. Complementary therapies in clinical practice, 20(1), 42-47.

Black, J.M., \& Hawks, J.K. (2009). Medical Surgical Nursing: Clinical Management for Positive Outcomes, Volume II, 7th Edition. Elsevier's Health Science Right Departement: Philadelphia

Cutshall, S. M., Anderson, P. G., Prinsen, S. K., Wentworth, L. J., Olney, T. L., Messner, P. K., ... \& Bauer, B. A. (2011). Effect of the combination of music and nature sounds on pain and anxiety in cardiac surgical patients: a randomized study. Alternative Therapies in Health \& Medicine, 17(4).

Cutshall, S. M., Wentworth, L. J., Engen, D., Sundt, T. M., Kelly, R. F., \& Bauer, B. A. (2010). Effect of massage therapy on pain, anxiety, and tension in cardiac surgical patients: a pilot study. Complementary therapies in clinical practice, 16(2), 92-95.

Guo, P. (2015). Preoperative education interventions to reduce anxiety and improve recovery among cardiac surgery patients: a review of randomised controlled trials. Journal of Clinical Nursing, 24(1-2), 34-46.
Guo, P., East, L., \& Arthur, A. (2012). A preoperative education intervention to reduce anxiety and improve recovery among Chinese cardiac patients: a randomized controlled trial. International Journal of Nursing Studies, 49(2), 129-137.

Heidari, S., Babaii, A., Abbasinia, M., Shamali, M., Abbasi, M., \& Rezaei, M. (2015). The effect of music on anxiety and cardiovascular indices in patients undergoing coronary artery bypass graft: a randomized controlled trial. Nursing and midwifery studies, 4(4).

Ko, Y. L., \& Lin, P. C. (2012). The effect of using a relaxation tape on pulse, respiration, blood pressure and anxiety levels of surgical patients. Journal of clinical nursing, 21(5-6), 689-697.

Millar, K., Jelicic, M., Bonke, B., \& Asbury, A. J. (1995). Assessment of preoperative anxiety: comparison of measures in patients awaiting surgery for breast cancer. British Journal of Anaesthesia, 74(2), 180-183.

Miozzo, A. P., Stein, C., Bozzetto, C. B., \& Plentz, R. D. M. (2016). Massage therapy reduces pain and anxiety after cardiac surgery: A systematic review and meta-analysis of randomized clinical trials. Clinical Trials and Regulatory Science in Cardiology, 23, $1-8$.

Nigussie, S., Belachew, T., \& Wolancho, W. (2014). Predictors of preoperative anxiety among surgical patients in Jimma University specialized teaching hospital, South Western Ethiopia. BMC surgery, 14(1), 67.

Pittman, S., \& Kridli, S. (2011). Music intervention and preoperative anxiety: an integrative review. International nursing review, 58(2), 157-163.

Rejeh, N., Heravi-Karimooi, M., Vaismoradi, M., \& Jasper, M. (2013). Effect of systematic relaxation techniques on anxiety and pain in older patients undergoing abdominal surgery. 
International journal of nursing practice, 19(5), 462-470.

Seifi, Z., Beikmoradi, A., Oshvandi, K., Poorolajal, J., Araghchian, M., \& Safiaryan, R. (2014). The effect of lavender essential oil on anxiety level in patients undergoing coronary artery bypass graft surgery: A doubleblinded randomized clinical trial. Iranian journal of nursing and midwifery research, 19(6), 574.

Shahmansouri, N., Janghorbani, M., Salehi Omran, A., Karimi, A. A., Noorbala, A. A., Arjmandi, A., \& Nikfam, S. (2014). Effects of a psychoeducation intervention on fear and anxiety about surgery: randomized trial in patients undergoing coronary artery bypass grafting. Psychology, health \& medicine, 19(4), 375-383.

Sharif, F., Shoul, A., Janati, M., Kojuri, J., \& Zare, N. (2012). The effect of cardiac rehabilitation on anxiety and depression in patients undergoing cardiac bypass graft surgery in Iran. BMC cardiovascular disorders, 12(1), 40.

Smeltzer, S. C., Bare, B. G., Hinkle, J. L., \& Cheever, K. H. (2010). Brunner \& suddarth textbook of medical-surgical nursing. Philadelphia: Lippincott Williams \& Wilkins.

Sulastini, S., Mediani, H. S., Fitria, N., \& Nugraha, B. A. (2019). Effect of Progressive Muscle Relaxation on Anxiety in Congestive Heart Failure Patients. Jurnal Keperawatan Soedirman, 14(2).

Tully, P. J., \& Baker, R. A. (2012). Depression, anxiety, and cardiac morbidity outcomes after coronary artery bypass surgery: a contemporary and practical review. Journal of geriatric cardiology: JGC, 9(2), 197.

Wang, T., Huang, J., Ho, W., \& Chiou, A. (2016). Effects of a supportive educational nursing care programme on fatigue and quality of life in patients with heart failure: a randomised controlled trial. European
Journal Of Cardiovascular Nursing, $15(2)$, 157-167. doi: $10.1177 / 1474515115618567$

World Health Organization. (2014). Global Status Report on Noncommunicable Yilmaz, M., Sezer, H., Gürler, H., \& Bekar, M. (2012). Predictors of preoperative anxiety in surgical inpatients. Journal of clinical nursing, 21(7-8), 956-964 